\title{
Annual cycle of horizontal in-mixing into the lower tropical stratosphere
}

\author{
Paul Konopka, ${ }^{1}$ Jens-Uwe Grooß, ${ }^{1}$ Felix Plöger, ${ }^{1}$ and Rolf Müller ${ }^{1}$ \\ Received 22 February 2009; revised 22 June 2009; accepted 30 June 2009; published 9 October 2009.
}

[1] Based on the HALOE and SHADOZ observations of ozone $\left(\mathrm{O}_{3}\right)$ and on a simple conceptual model of transport and photochemistry, the seasonality of $\mathrm{O}_{3}$ within the stratospheric part of the tropical tropopause layer (TTL) extending between 360 and $420 \mathrm{~K}$ potential temperature is discussed. We show that the seasonality of $\mathrm{O}_{3}$ diagnosed on pressure $(p)$ surfaces has a significantly larger annual cycle compared with the same kind of analysis on surfaces with constant potential temperature $(\theta)$, in particular around $p=80 \mathrm{hPa}$, where the strongest annual variation in tropical temperature occurs. Thus by using $\theta$ instead of $p$ as the vertical coordinate, the (seasonal) adiabatic variability is removed, and consequently, a much smaller seasonal cycle of $\mathrm{O}_{3}$ remains, which can be understood as a consequence of chemistry, cross-isentropic transport (upwelling), and horizontal, i.e., quasi-isentropic, transport (in-mixing). Furthermore, we show that the observed, $\theta$-related seasonality of $\mathrm{O}_{3}$, with highest values during boreal summer, cannot be understood only by photolytical $\mathrm{O}_{3}$ production in slowly rising air masses, which are well isolated from the extratropics. By using the SHADOZ climatology at $\theta=360 \mathrm{~K}$ and quantifying the photochemical production of $\mathrm{O}_{3}$ in ascending air above $\theta=360 \mathrm{~K}$, we determine the residual variability between the observations (SHADOZ, HALOE) and the calculated $\mathrm{O}_{3}$ values and, consequently, interpret this residuum as horizontal in-mixing from the extratropical stratosphere. We find that between 380 and $420 \mathrm{~K}$, in-mixing contributes to about $40 \%$ of the observed $\mathrm{O}_{3}$ mixing ratios during boreal summer.

Citation: Konopka, P., J.-U. Grooß, F. Plöger, and R. Müller (2009), Annual cycle of horizontal in-mixing into the lower tropical stratosphere, J. Geophys. Res., 114, D19111, doi:10.1029/2009JD011955.

\section{Introduction}

[2] The tropical tropopause layer (TTL) has been described as a transition layer coupling the convectively dominated free troposphere with the Brewer-Dobson circulation in the stratosphere. Whereas the upward transport in the free troposphere is locally generated (convection, turbulence), the extratropical wave drag drives the meridional transport and the tropical upwelling within the BrewerDobson circulation (the so-called "downward control" principle [Haynes et al., 1991; Holton et al., 1995; Callaghan and Salby, 2001; Fueglistaler et al., 2009]).

[3] As recently deduced from satellite and in situ data, the composition of air within the TTL, in particular at the tropical tropopause (i.e., around $p \approx 100 \mathrm{hPa}$ or $\theta \approx 380 \mathrm{~K}$; $p$, pressure; $\theta$, potential temperature) shows a clear seasonal cycle. In particular, high water vapor $\left(\mathrm{H}_{2} \mathrm{O}\right)$, high ozone $\mathrm{O}_{3}$, low carbon monoxide (CO) during summer (seasons are relative to the northern hemisphere) alternate with low $\mathrm{H}_{2} \mathrm{O}$, low $\mathrm{O}_{3}$ and high $\mathrm{CO}$ during winter [Folkins et al., 2006; Schoeberl et al., 2006; Randel et al., 2007]. Furthermore, Randel et al. [2007] also inferred that a large annual

\footnotetext{
${ }^{1}$ ICG-1: Stratosphere, Forschungszentrum Jülich, Jülich, Germany.
}

Copyright 2009 by the American Geophysical Union. 0148-0227/09/2009JD011955 cycle of $\mathrm{O}_{3}$ (and $\mathrm{CO}$ ) can be diagnosed on constant $p$ levels within a narrow vertical layer extending around $80 \mathrm{hPa}$ and that this annual cycle is approximately in-phase with the wellknown variation in tropical temperature above the tropical tropopause [Reed and Vlcek, 1969] that also has the largest amplitude around $80 \mathrm{hPa}$.

[4] The composition of air within the TTL, in particular the question of how well the tropics are isolated from the extratropics, has been intensively discussed in the past. Although the existence of a mixing barrier between the tropics and extratropics can be diagnosed from the meteorological winds [Chen, 1995; Plumb, 1996; Haynes and Shuckburgh, 2000], evidence of horizontal in-mixing, i.e., of meridional, quasi-isentropic transport from the extratropics into the TTL, was frequently observed in measurements of tracer species [Volk et al., 1996; Avallone and Prather, 1997; Folkins et al., 1999].

[5] Using ozone sondes and aircraft observations of $\mathrm{N}_{2} \mathrm{O} / \mathrm{O}_{3}$ correlations, signatures of stratospheric contributions were found within the TTL above $14 \mathrm{~km}$ and well below the tropopause, identifying this region as a transition zone separating the troposphere from the stratosphere [Tuck et al., 1997]. Recently, Marcy et al. [2007] showed that more than $60 \%$ of their airborne in situ $\mathrm{HCl}$ observations within the TTL (up to $\approx 100$ pptv below $\theta \approx 390 \mathrm{~K}$ ) have stratospheric sources and that this $\mathrm{HCl}$ is well correlated with $\mathrm{O}_{3}$. 

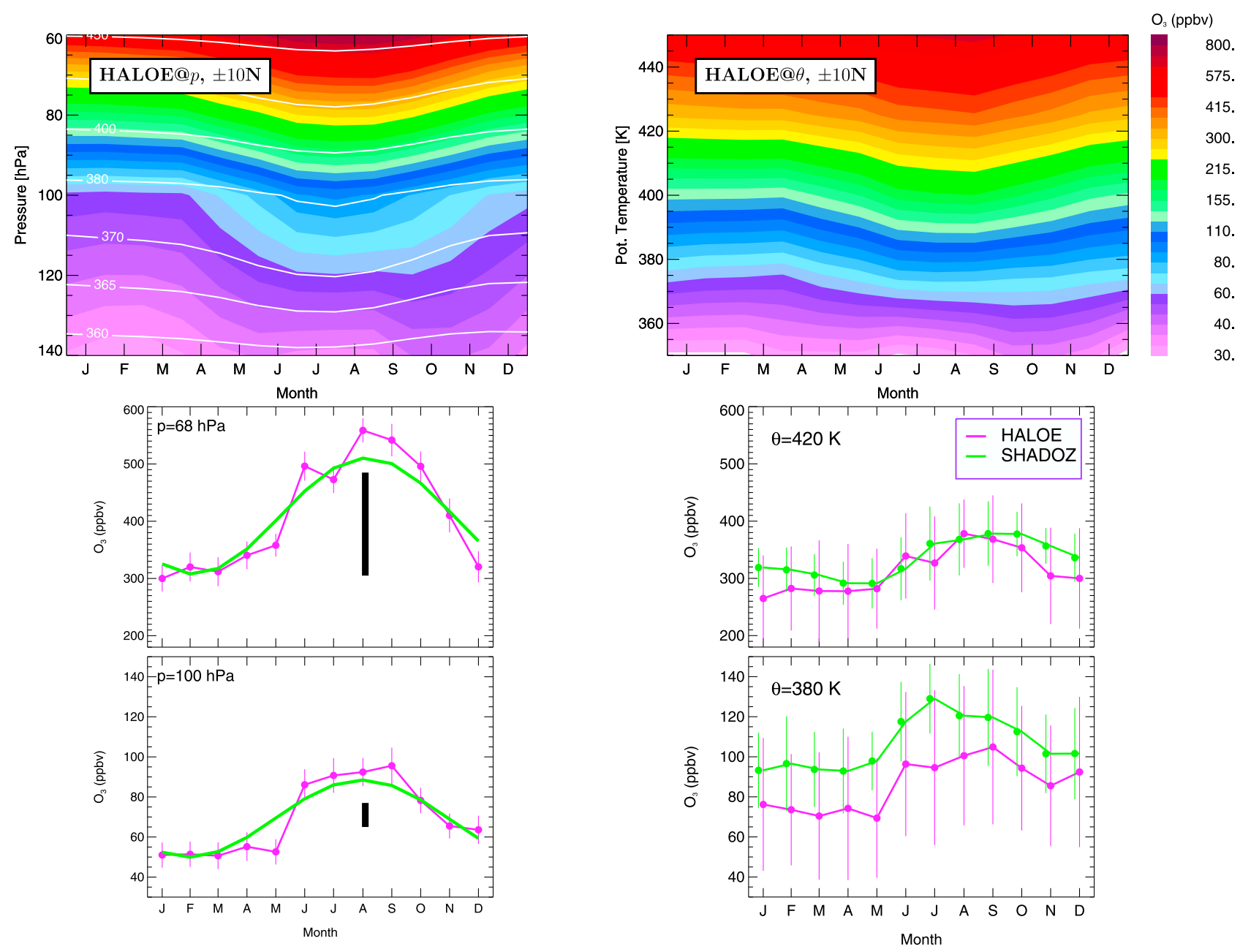

Figure 1. Seasonal cycle of $\mathrm{O}_{3}$ within the TTL averaged within the latitude range $\pm 10^{\circ} \mathrm{N}$ using the (left) pressure $p$ and (right) potential temperature $\theta$ as the vertical coordinate as derived from the 10-year HALOE climatology [Grooß and Russell, 2005]. In the middle and bottom panels, the corresponding time series are compared with the SHADOZ observations. The black bars estimate the amplitude of the seasonal cycle of $\mathrm{O}_{3}$ on $p$ levels resulting from the seasonal adiabatic variability, i.e., obtained by assuming that $\partial \mathrm{O}_{3} /\left.\partial t\right|_{\theta=\text { const. }}=0$ (see text for details).

[6] The main purpose of this study is to discuss how the horizontal in-mixing does contribute to the seasonality of $\mathrm{O}_{3}$ within the stratospheric part of the TTL, roughly confined by potential temperature values $\theta=360 \mathrm{~K}$ (zero clear sky radiative heating) and $420 \mathrm{~K}$.

\section{Annual Cycle of Tropical $\mathrm{O}_{3}$}

[7] To analyze the annual cycle of tropical $\mathrm{O}_{3}$ we use the satellite data collected in the 10-year climatology of the Halogen Occultation Experiment (HALOE [Groo $\beta$ and Russell, 2005]) and the in situ observations of the Southern Hemisphere ADditional OZonesondes (SHADOZ) network [Thompson et al., 2007]. In Figure 1 (top left and right), HALOE $\mathrm{O}_{3}$ climatology based on observations from 1991 to 2002 is shown, averaged over the latitude range $\pm 10^{\circ} \mathrm{N}$, with $p$ and $\theta$ as the vertical coordinate, respectively. Even though HALOE samples the tropics only intermittently in a single year, the 10-year climatology contains enough data for an average annual cycle of observations on a monthly basis. Furthermore, because the HALOE instrument did not measure temperature, the $\theta$ coordinate in the original HALOE data set was derived from the UKMO temperature [Grooß and Russell, 2005].

[8] Whereas a clear maximum in summer can be seen at each $p$ level above $\approx 120 \mathrm{hPa}$, the use of $\theta$ as the vertical coordinate significantly reduces the seasonal variability of $\mathrm{O}_{3}$ (see $\mathrm{O}_{3}$ along the white isentropes plotted in the top left panel). An example of this effect can be seen at $p=68 / 100 \mathrm{hPa}$ and $\theta=420 / 380 \mathrm{~K}$ (middle and bottom panels), where both the HALOE (pink) and the SHADOZ (green) time series are shown. The SHADOZ time series on $p$ levels are harmonic fits reported by Randel et al. [2007]. Using the observed temperature profiles, the $p$-related observations were transformed to $\theta$ levels (right middle and bottom panels). Each green circle represents the average value over 7 stations (from 11 available SHADOZ stations, the 7 stations closest to the equator were chosen), the error bars denote the station-to-station variance. The error bars of the HALOE climatology denote the standard deviation of all HALOE observations within the considered month and $\pm 10^{\circ} \mathrm{N}$ latitude range. 


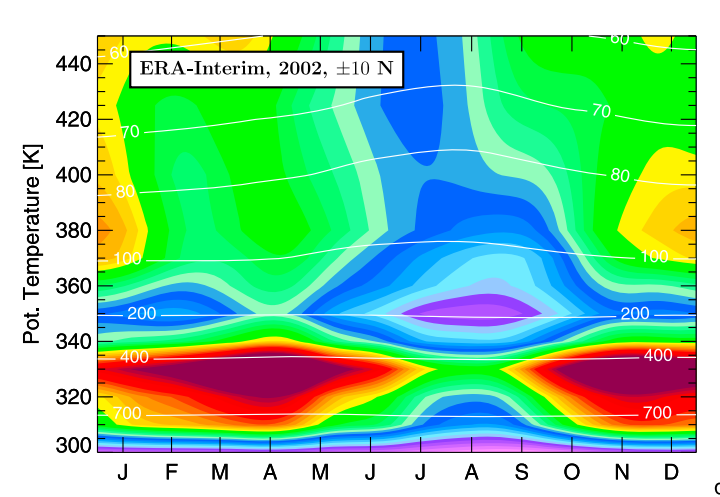

$\mathrm{d} \theta / \mathrm{dt}[\mathrm{K} / \mathrm{day}]$
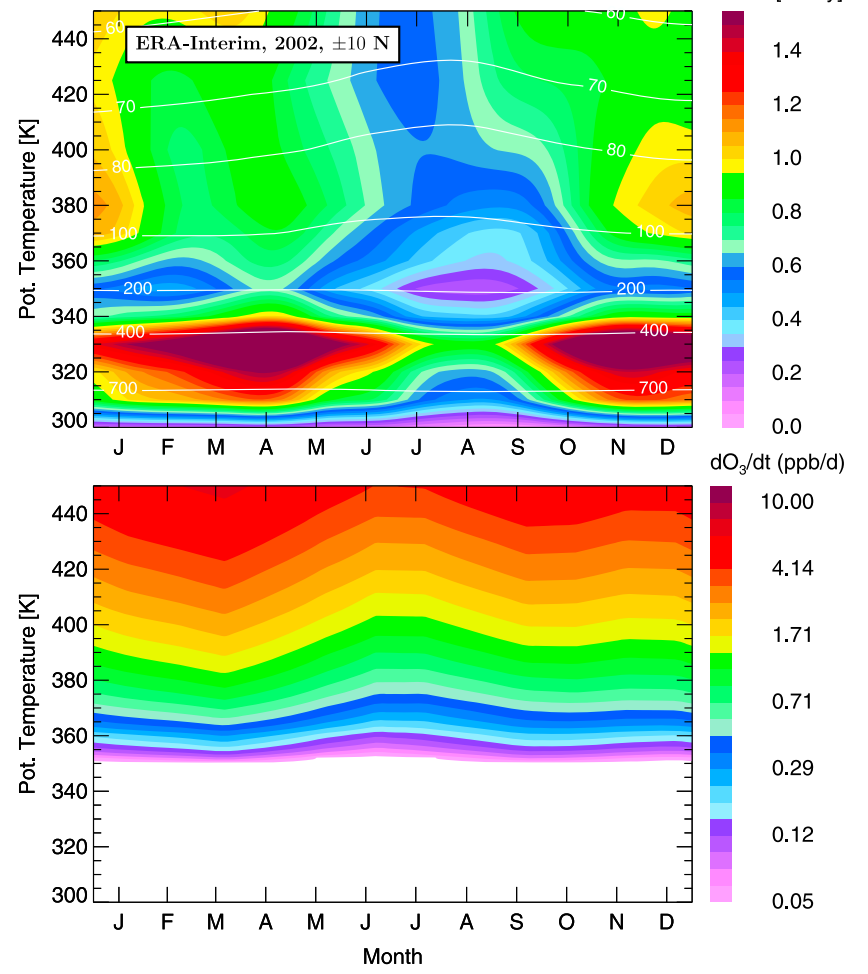

Figure 2. (top) Seasonality of upwelling described in terms of $\dot{\theta}$ averaged zonally and within the $\pm 10^{\circ} \mathrm{N}$ range derived from the recent interim multiyear ECMWF reanalysis (ERA-Interim [Fueglistaler et al., 2008]) (black, $p$ levels). (bottom) Ozone production rate, $d \mathrm{O}_{3} / d t$, at the equator.

[9] It should be noted that the horizontal and vertical resolution of the HALOE instrument is of the order of $400 \mathrm{~m}$ and $2 \mathrm{~km}$, respectively [Brühl et al., 1996], whereas the vertical resolution of the ozone sondes of the SHADOZ network is much higher, i.e., between 150 and $200 \mathrm{~m}$ [Thompson et al., 2007]. On the other hand, the HALOE observations sampled over the 1991-2002 period cover the considered $\pm 10^{\circ} \mathrm{N}$ latitude range almost uniformly. In contrast, the SHADOZ climatology is biased by the geographic positions of the 7 station considered of which 5 are located in the southern hemisphere. Above the tropical tropopause, the accuracy of both instruments is better than $10 \%$ and $5 \%$ for the HALOE, and SHADOZ data, respectively [Bhatt et al., 1999; Thompson et al., 2007]. Between 100 and $140 \mathrm{hPa}, \mathrm{HALOE}$ accuracy decreases to $25 \%$ and the climatological average is biased by the fact that cloud-free conditions are necessary for the HALOE retrieval algorithm. Further, although at $p=100 \mathrm{hPa}$, the SHADOZ and HALOE data agree reasonably well, there is an offset of about $20 \mathrm{ppbv}$ at $\theta=380 \mathrm{~K}$ mainly due to the difference between the temperatures measured by the SHADOZ sondes and the UKMO-based HALOE temperature.

[10] To estimate how the choice of the vertical coordinate influences the seasonality of $\mathrm{O}_{3}$, let us compare the time variation of $\mathrm{O}_{3}$ on $\theta$ and $p=$ const. surface, i.e.:

$$
\left.\frac{\partial \mathrm{O}_{3}}{\partial t}\right|_{\theta}=\left.\frac{\partial \mathrm{O}_{3}}{\partial t}\right|_{p}+\left.\frac{\partial \mathrm{O}_{3}}{\partial p} \frac{d p}{d t}\right|_{\theta}
$$

Assuming that ozone variation at $\theta=$ const. is negligible, one obtains

$$
\left.\frac{\partial \mathrm{O}_{3}}{\partial t}\right|_{p}=-\left.\frac{\partial \mathrm{O}_{3}}{\partial p} \frac{d p}{d t}\right|_{\theta}=-\left.\frac{\partial \mathrm{O}_{3}}{\partial p} \frac{1}{\kappa} \frac{p}{T} \frac{d T}{d t}\right|_{\theta}
$$

where $d p / d t$ was derived from the definition of the potential temperature, $\theta=T\left(p_{0} / p\right)^{\kappa}$. In log-pressure coordinates with $z=-H \ln \left(p / p_{0}\right)(H=7 \mathrm{~km})$, equation (2) can be rewritten as

$$
\left.\frac{\partial \mathrm{O}_{3}}{\partial t}\right|_{z}=\left.\frac{\partial \mathrm{O}_{3}}{\partial z} \frac{1}{\kappa} \frac{H}{T} \frac{d T}{d t}\right|_{\theta}
$$

Finally, assuming a sinusoidal variation of $\mathrm{O}_{3}$ and $T$ of the form $f=\bar{f}+\Delta f \sin (\omega t+\phi)$ and $\Delta T / T \approx \Delta T / \bar{T}$, we obtain

$$
\left.\frac{\Delta \mathrm{O}_{3}}{\overline{\mathrm{O}}_{3}}\right|_{z}=\left.\frac{d \ln \overline{\mathrm{O}}_{3}}{d z} \frac{H}{\kappa} \frac{\Delta T}{\bar{T}}\right|_{\theta}
$$

Thus using the numerical values of $d \ln \bar{O}_{3} / d z$ and $\Delta T / \bar{T}$ given by Randel et al. [2007] (Figures 3 and 5), one obtains $\Delta \mathrm{O}_{3}=90,80,6$ ppbv at $p=68,83$ and $100 \mathrm{hPa}$ where $\bar{O}_{3}$ was set to 400,200 and $70 \mathrm{ppbv}$, respectively. The resulting variability $\left(2 \Delta \mathrm{O}_{3}\right)$ is shown in Figure 1 as black vertical lines. Note that this adiabatic variability (defined as $\partial \mathrm{O}_{3} / \partial t=0$ at $\theta=$ const) is only slightly smaller than the full variability on $p$ surfaces of the harmonic fits of the SHADOZ time series (green).

[11] We conclude that the seasonal variability of $\mathrm{O}_{3}$, and in particular its annual cycle, is much larger if pressure is used as the vertical coordinate instead of the potential temperature. This effect dominates around $p=80 \mathrm{hPa}$ (i.e., where $\Delta \mathrm{O}_{3} / \bar{O}_{3}$ has a maximum) where also the strongest annual variation in tropical temperature occurs. Consequently, the large annual cycle of $\mathrm{O}_{3}$ at $p$ levels as recently discussed by Randel et al. [2007] contains a significant adiabatic part that can be removed if the annual cycle is diagnosed on $\theta$ levels. Thus the analysis on $\theta$ surfaces allows us to separate more precisely the contribution of the cross-isentropic (diabatic) transport from the horizontal in-mixing on the seasonality of $\mathrm{O}_{3}$. We pursue this idea in the next section.

\section{3. $\mathrm{O}_{3}$ Budget Within the TTL: A Simple Model}

[12] $\mathrm{O}_{3}$ in the TTL is determined, first, by the tropospheric $\mathrm{O}_{3}$ mixing ratios which define the entry level, second, by photolytical ozone production during ascent in the TTL and, third, by horizontal in-mixing of $\mathrm{O}_{3}$-rich stratospheric air. In the following, we discuss the influence of all these processes on the distribution of $\mathrm{O}_{3}$ within the upper part of the TTL (i.e., above $\theta=360 \mathrm{~K}$ and between $\pm 10^{\circ} \mathrm{N}$ ).

[13] Here we construct a simple conceptual model describing these three processes that influence ozone. In particular, we use two-dimensional trajectories (i.e., in time $\times \theta$ space) to describe vertical transport and calculate photolytical ozone production along such trajectories. The change of the $\theta$ coordinate of the air parcels is driven by $\dot{\theta}$ depicted in Figure 2 (top) whereas the chemical production of $\mathrm{O}_{3}$ along each trajectory is derived from the ozone production rate $d \mathrm{O}_{3} / d t$ shown in Figure 2 (bottom). 


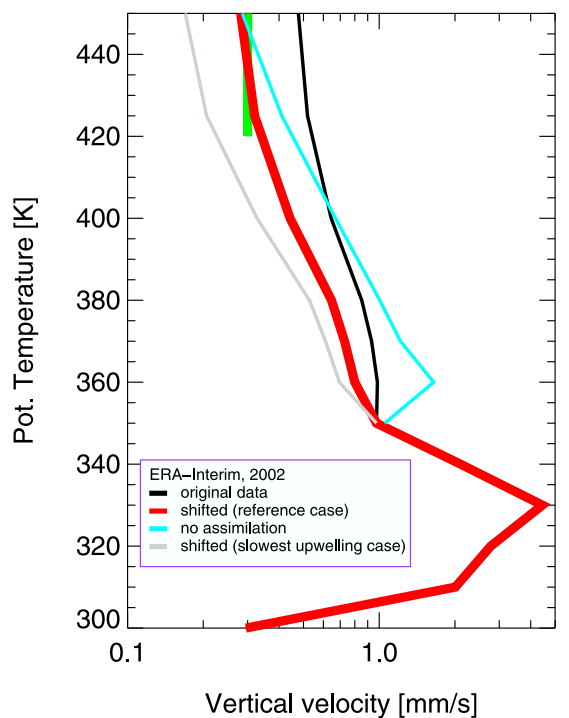

Figure 3. The annual mean of the vertical velocity $w$ (in $\mathrm{mm} / \mathrm{s}$ ) derived from $\dot{\theta}$ shown in Figure 2 (top) (thin black line). The thick green line denotes the typical value of the mean ascent estimated from the upward propagation of the $\mathrm{H}_{2} \mathrm{O}$ tape recorder signal, i.e., $w \approx 0.3 \mathrm{~mm} / \mathrm{s}$ [Mote et al., 1998; Niwano et al., 2003; Schoeberl et al., 2008]. To estimate the slowest realistic ascent rate, we reduce $\dot{\theta}$ above $350 \mathrm{~K}$ in order to match the thick green line (thick red line). This scenario is used further in this paper. To analyze the sensitivity of our results, we also consider two additional scenarios for $\dot{\theta}$ (blue and gray line; for details, see text).

[14] $\dot{\theta}$ is derived from the diabatic heat budget based on the recent ECMWF reanalysis ERA-Interim [Simmons et al., 2006]. Using the relation $\dot{\theta} / \theta=Q /\left(T c_{p}\right)$ [Holton, 1992], where $T$ is the temperature and $Q$ the diabatic heating/cooling rate per unit mass (in $\mathrm{J} / \mathrm{kg} \cdot \mathrm{K}$ ), we follow the procedure described by Fueglistaler et al. [2008] and calculate $Q / c_{p}$ from the temperature tendencies due to radiation, latent heat, mixing and assimilation increments stored in ECMWF data sets.

[15] Figure 2 (top) shows $\dot{\theta}$ derived in this way from ERA-Interim data for 2002 and averaged zonally as well as within the $\pm 10^{\circ} \mathrm{N}$ range. Below $\theta \approx 350 \mathrm{~K}$, a semiannual pattern of convection is obvious with two maxima around April and the end of November, in qualitative agreement with the seasonality of the cloud occurrence and water vapor in this latitude range observed from the satellites [Liu et al., 2007]. Above this level, in particular above the level of zero clear sky radiation $(\theta \approx 360 \mathrm{~K})$, the semiannual cycle gradually transforms into an annual cycle of upwelling around $420 \mathrm{~K}$, i.e., into the ascending branch of the Brewer-Dobson circulation.

[16] The annual mean of the vertical velocity $w$ (in $\mathrm{mm} / \mathrm{s}$ ) derived from Figure 2 (top) is plotted in Figure 3 as a thin black line.

[17] The velocity $w$ in $\mathrm{mm} / \mathrm{s}$ was inferred from $\dot{\theta}$ in $\mathrm{K} / \mathrm{d}$ using $w=\dot{\theta} \cdot d z / d \theta$ with $d z / d \theta$ deduced from the SHADOZ climatology described in the previous section. Fueglistaler et al. [2008] reported large uncertainties in the magnitude of $\dot{\theta}$ in the region between 350 and $360 \mathrm{~K}$ with values varying between 0.4 (ERA-Interim) and $1.0 \mathrm{~K} / \mathrm{d}$ (ERA-40), whereas the latter values result in too strong tropical upwelling. Furthermore, mean vertical velocity derived from the upward propagation of the $\mathrm{H}_{2} \mathrm{O}$ tape recorder signal have a minimum around $60 \mathrm{hPa}$ of the order of $0.5 \mathrm{~K} / \mathrm{d}(\approx 0.3 \mathrm{~mm} / \mathrm{s}$ [Mote et al., 1998; Niwano et al., 2003; Schoeberl et al., 2008], thick green line in Figure 3).

[18] To take these uncertainties into account, we shift $\dot{\theta}$ above $\theta=350 \mathrm{~K}$ toward lower values using a timeindependent offset and replace $\dot{\theta}$ with $\dot{\theta}\left[1-\gamma(\theta-350)^{\frac{1}{2}}\right]$ with $\gamma=0.035$ and 0.55 . The thick red (default) and thin gray lines in Figure 3 show the corresponding annual means. Whereas the first scenario reproduces the upward vertical velocity of the $\mathrm{H}_{2} \mathrm{O}$ tape recorder (at $\theta=450 \mathrm{~K}$, the red line crosses the green one), the second case approximates the lower bound of the tropical vertical velocities recently discussed by Yang et al. [2008] (Figure 5) where radiative heating rate calculations with the SHADOZ climatology of $\mathrm{O}_{3}$ and temperature as well as the $\mathrm{H}_{2} \mathrm{O}$ profiles measured with the a frost-point hygrometer were used. With this scenario we make sure that slowest reasonable upwelling is taken into account even though the coverage of the SHADOZ $\left(-15^{\circ} \mathrm{S}-10^{\circ} \mathrm{N}\right)$ data is more representative for the southern hemisphere and, consequently, the vertical velocities discussed by Yang et al. [2008] probably underestimate the upwelling in the $\pm 10^{\circ} \mathrm{N}$ range discussed here.

[19] In the following, we use these scenarios of a reduced $\dot{\theta}$ to estimate the upwelling in the lower tropical stratosphere. Both chosen corrections define scenarios that result in longer residence times than most estimates [Krüger et al., 2008; Plöger et al., 2009]. In particular, the mean residence times between $\theta=360$ and $380 \mathrm{~K}$ vary between 45 and 60 days, for the red and gray curves, respectively, with longest summer residence times given by 71 and 95 days. In this way, we obtain an upper bound of the possible photolytical production of $\mathrm{O}_{3}$ in the tropical lower stratosphere. In addition, to avoid some spurious transport due to the assimilation procedure [Schoeberl et al., 2003], we also use $\dot{\theta}$ calculated without the assimilation increments (thin blue line).

[20] Figure 2 (bottom) illustrates the seasonality of the ozone production rate, $d \mathrm{O}_{3} / d t$ at the equator $\left(\mathrm{O}_{3}\right.$ production through oxygen photolysis). Using $p$ as the vertical coordinate, $d \mathrm{O}_{3} / d t$ was determined with a photolytical model described by Becker et al. [2000]. The absolute values of $d \mathrm{O}_{3} / d t$ agree fairly well with published results [Osterman et $a l ., 1997]$ and show an exact semiannual cycle with maxima during the equinox indicating that only the zenith angle and the overhead column of $\mathrm{O}_{3}$ (overhead $\mathrm{O}_{3}$ column is defined in $p$ space and not in $\theta$ space) determine the value of $d \mathrm{O}_{3} / d t$ (not shown). By transferring these values from $p$ to $\theta$ coordinate, the annual cycle of the tropical tropopause pressure slightly modulates this cycle. For example, $p$ varies between 100 and $90 \mathrm{hPa}$ at $\theta=380 \mathrm{~K}$ in summer and winter, respectively, with the highest $d \mathrm{O}_{3} / d t$ in winter.

[21] Generally, the use of a mean vertical velocity in the tropospheric part of the TTL, i.e., roughly below $\theta=360 \mathrm{~K}$, strongly underestimates the real variability of transport dominated by rapid upward convective mass transport and slow large-scale subsidence. Furthermore, the modeling of the tropospheric ozone production, driven by hydrogen and nitrogen radicals [Wennberg et al., 1998], requires very 

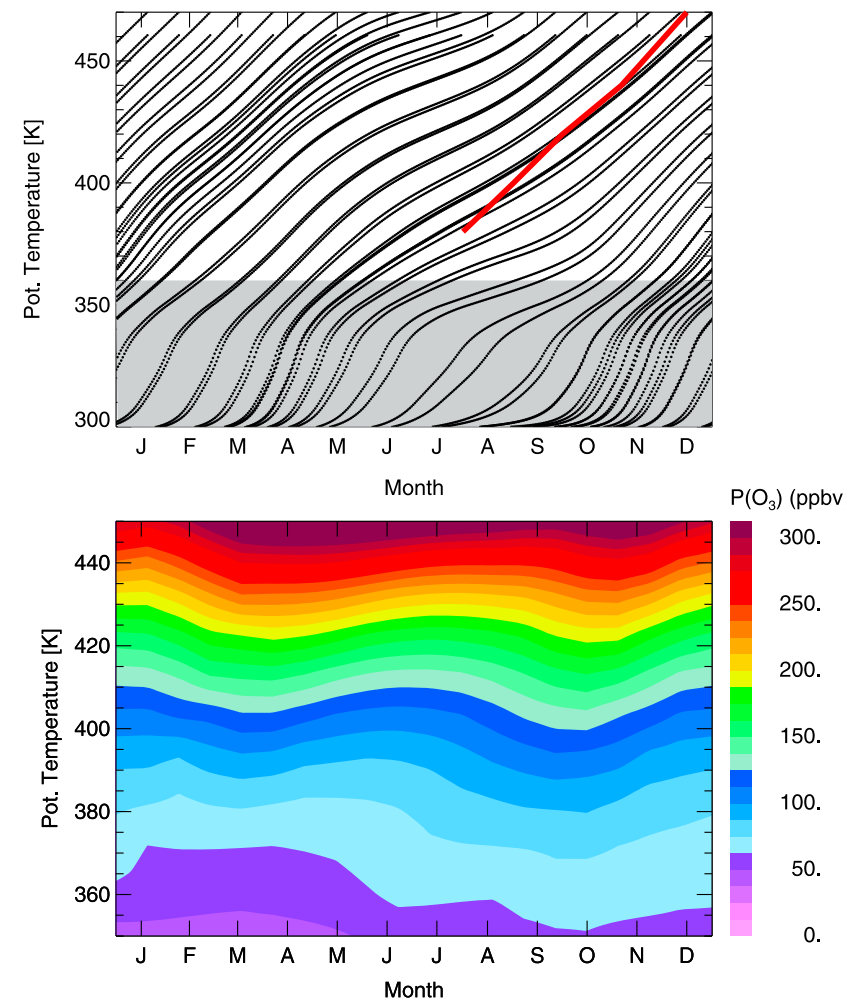

Figure 4. (top) Two-dimensional trajectories derived from the mean values of $\dot{\theta}$ shown in Figure 2 (top) and shifted toward lower values as described in the previous section (thick red line in Figure 3). The trajectories were started from all the points of the considered time- $\theta$ plane $(\Delta t=$ 10 day, $\Delta \theta=5 \mathrm{~K})$. Not all trajectories are shown. Within the gray region, i.e., below $360 \mathrm{~K}$, the $\mathrm{O}_{3}$ mixing ratios are overwritten with the SHADOZ climatology. The thick red line denotes the position of maxima of the $\mathrm{H}_{2} \mathrm{O}$ tape recorder (HALOE climatology, $\mathrm{H}_{2} \mathrm{O}+2 \mathrm{CH}_{4}$ ). (bottom) Photochemically formed and accumulated $\mathrm{O}_{3}, P\left(\mathrm{O}_{3}\right)$, calculated along the trajectories shown above. Here $d \mathrm{O}_{3} / d t$ plotted in Figure 2 (bottom) was used and the SHADOZ climatology was applied for the initial value at $\theta=360 \mathrm{~K}$.

detailed information on the atmospheric composition. We overcome these difficulties by confining our two-dimensional model to the region above $\theta=360 \mathrm{~K}$. For the lower boundary at $\theta=360 \mathrm{~K}$ (and for levels below) we apply the SHADOZ climatology discussed in the previous section.

\section{Model Results}

[22] The resulting idealized trajectories of ascending air masses and the mixing ratios of the photochemically formed $\mathrm{O}_{3}$ along these trajectories are shown in Figure 4 (top and bottom, respectively).

[23] In particular, the slope of the trajectories measures the residence time at a given $\theta$ level. Here only trajectories above $360 \mathrm{~K}$ contribute to our calculations (i.e., within the gray region in Figure 4 (top) $\mathrm{O}_{3}$ mixing ratios are overwritten with the SHADOZ climatology). The air parcels need approximately 4-5 months to overcome the distance between 370 and $450 \mathrm{~K}$ in rough agreement with the slope of the $\mathrm{H}_{2} \mathrm{O}+2 \mathrm{CH}_{4}$ tape recorder signal (the red line is derived from the position of the corresponding maxima in the HALOE climatology). The fastest diabatic ascent occurs in winter as a consequence of the seasonality of the tropical temperature.

[24] The accumulated, photochemically produced $\mathrm{O}_{3}$ along the trajectories, $\mathrm{P}\left(\mathrm{O}_{3}\right)$, is depicted in Figure 4 (bottom). Similar to the ozone production rates (Figure 2, bottom), the seasonality of $\mathrm{P}\left(\mathrm{O}_{3}\right)$ shows a strong semiannual cycle for $380<\theta<450 \mathrm{~K}$. In addition, this semiannual variability is overlaid by a weak annual cycle with a maximum in summer.

[25] This weak annual cycle of $\mathrm{P}\left(\mathrm{O}_{3}\right)$ is driven by the seasonal variation of the temperature and, following our analysis, can be understood as a superposition of two opposite annual cycles: a smaller cycle of $d \mathrm{O}_{3} / d t$ with a maximum in winter (see Figure 2, bottom) and a slightly stronger cycle of upwelling with the longest residence time (and strongest contribution to $\mathrm{P}\left(\mathrm{O}_{3}\right)$ ) in summer. Generally, longer residence times can lead to a photochemical summer maximum in $\mathrm{P}\left(\mathrm{O}_{3}\right)$ but our sensitivity studies indicate that this effect cannot completely explain the observed summer maximum, in particular within the $\theta$ range between 380 and $420 \mathrm{~K}$ (Figure 1, top right). Here the values of $\mathrm{P}\left(\mathrm{O}_{3}\right)$ are comparable with the observations only for unrealistically long residence times within the stratospheric part of the TTL (of the order of one year). The reason for this small contribution to $\mathrm{P}\left(\mathrm{O}_{3}\right)$ is low values of $d \mathrm{O}_{3} / d t$ at those altitudes.

[26] Finally, we determine the residuum, $\Delta \mathrm{O}_{3}$, between the HALOE or SHADOZ climatology and the photochemically produced $\mathrm{P}\left(\mathrm{O}_{3}\right)$ shown in Figure 4 (bottom). We interpret the corresponding fraction, i.e., $\Delta \mathrm{O}_{3} / \mathrm{O}_{3}$ in $\%$, as a result of horizontal in-mixing from the sub- and extratropics into the considered $\pm 10^{\circ} \mathrm{N}$ band whereas both advection driven by the horizontal winds and mixing driven by breaking planetary waves contribute to such transport. The percentages of $\Delta \mathrm{O}_{3} / \mathrm{O}_{3}$, inferred both from the HALOE and SHADOZ climatology, are shown in Figure 5 (top and bottom, respectively).

[27] Thus there is a large annual cycle of in-mixing of $\mathrm{O}_{3}$ into the tropical stratosphere, with the highest contributions (up to $50 \%$ ) between 380 and $420 \mathrm{~K}$ during boreal summer and with slightly higher values derived from the SHADOZ climatology. Furthermore, the SHADOZ-based results show a more pronounced semiannual cycle if compared with the HALOE-based analysis. The pattern deduced from the HALOE- and SHADOZ-based analysis becomes more similar if the HALOE climatology between $-15^{\circ} \mathrm{N}$ and the equator (instead of $\pm 10^{\circ} \mathrm{N}$ ) is used (not shown). This is consistent with the fact that most (5 out of 7 ) of the SHADOZ stations are in the southern hemisphere and, consequently, do not uniformly cover the latitude range between $\pm 10^{\circ} \mathrm{N}$. The differences in the absolute values probably result from the lower accuracy and coarser vertical resolution of the HALOE data as well as from the different temperatures used to transform $p$-related data on the $\theta$ surfaces (see discussion related to Figure 1).

[28] The pattern of in-mixing shows only a weak dependence on the assumed scenarios of upwelling (see Figure 3) although the absolute values vary for summer conditions between 30 and $60 \%$ for the slowest (gray line in Figure 3) and fastest ascent scenario (ERA-Interim with no assimila- 

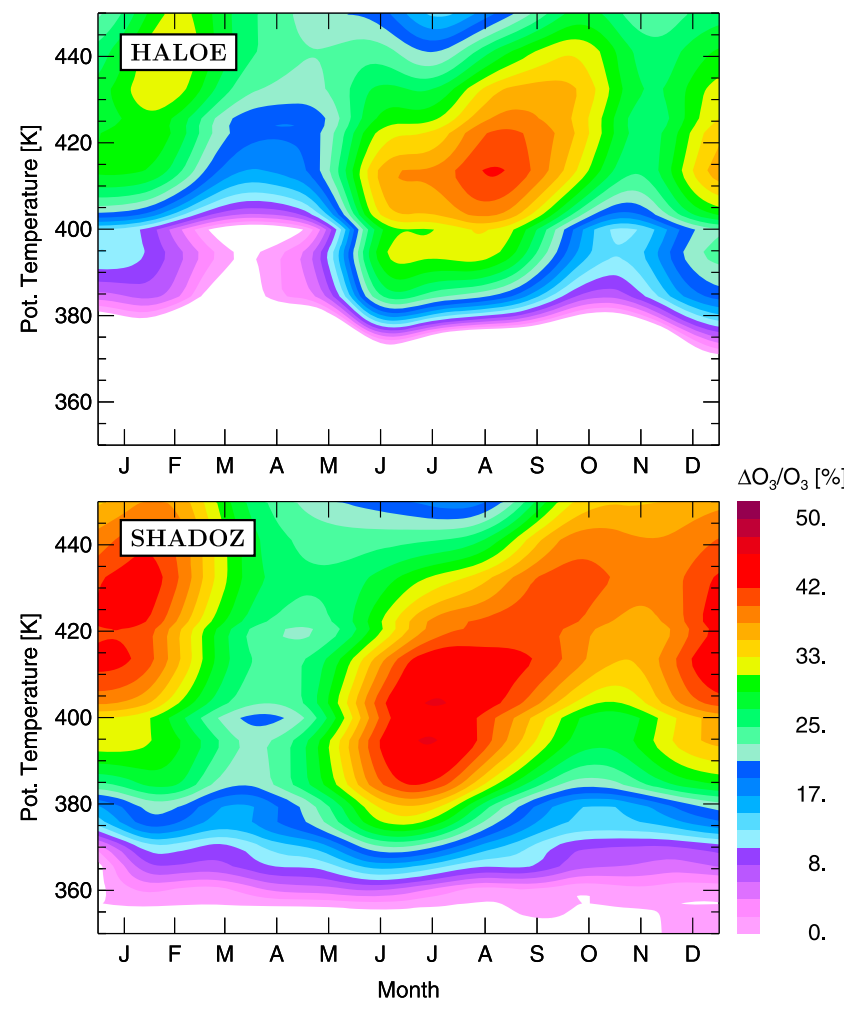

Figure 5. Fraction of in-mixed $\mathrm{O}_{3}$, i.e., $\Delta \mathrm{O}_{3} / \mathrm{O}_{3}$ in $\%$, derived from the difference between the climatology (HALOE, top; SHADOZ, bottom) and the accumulated $P\left(\mathrm{O}_{3}\right) . \Delta \mathrm{O}_{3}$ results from the horizontal in-mixing of $\mathrm{O}_{3}$-rich mid- and high-latitude stratospheric air into the lower tropical stratosphere.

tion, blue line in Figure 3), respectively. Note that these differences result from different contributions of the photochemistry along the trajectories, i.e., longer residence time implicates more photochemically produced $\mathrm{O}_{3}$ and, following our residual analysis, less in-mixing. On the other hand, a pure trajectory calculation becomes more questionable for longer residence times where impact of in-mixing becomes more likely. Above $\theta=420 \mathrm{~K}$, the chemical production of $\mathrm{O}_{3}$ increases very fast and, consequently, the fraction of the in-mixed $\mathrm{O}_{3}$ decreases strongly. By shifting the lower boundary of the model from $\theta=360$ to $\theta=370 \mathrm{~K}$ the inferred fractions of in-mixing decrease by less than $5 \%$.

\section{Discussion and Conclusions}

[29] The presented study shows that the annual cycle of $\mathrm{O}_{3}$ within the lower tropical stratosphere diagnosed on pressure levels is much more pronounced compared with a similar analysis on levels with $\theta=$ const. Whereas a significant part of the $p$-related variability can be understood as an adiabatic effect on a seasonal scale, i.e., caused by the annual cycle of the tropical temperature (and, consequently, by the annual cycle of $\theta$ on $p=$ const levels), our analysis on $\theta$ levels shows a much smaller amplitude of $\mathrm{O}_{3}$, in agreement with similar results discussed by Fueglistaler et al. [2009]. Furthermore, our $\theta$-related analysis allows us to quantify the contributions of the cross isentropic transport (i.e., diabatic upwelling), quasi-isentropic transport (i.e., in- mixing) and photochemistry to the observed seasonality of $\mathrm{O}_{3}$ in the lower tropical stratosphere.

[30] The contribution of photolytical production strongly increases with altitude and dominates the fraction of $\mathrm{O}_{3}$ above $\approx 440 \mathrm{~K}$ in agreement with previous studies [see, e.g., Avallone and Prather, 1997]. In particular, the photochemistry shows a pronounced semiannual cycle where the highest photolytical production occurs twice per year during the equinox. Below this level, in particular below $\theta=420 \mathrm{~K}$, transport rather than photochemistry influences a significant fraction of $\mathrm{O}_{3}$.

[31] Our analysis of the residuum between the observed $\mathrm{O}_{3}$ and the calculated $\mathrm{O}_{3}$ (i.e., tropospheric contribution + photolytical production) shows that this difference, interpreted here as in-mixing, is significant even if very conservative assumptions are made on the vertical ascent (slower than $\mathrm{H}_{2} \mathrm{O}$ tape recorder) and on the ozone production (equator values). Between June and August, the highest values around $40 \%$ were found in the $\theta$ range between 380 and $420 \mathrm{~K}$.

[32] Our analysis also shows that the effect of reduced upwelling in summer and, consequently, enhanced $\mathrm{O}_{3}$ production due to longer residence times in the lower tropical stratosphere is too weak to explain the observed summer maximum in $\mathrm{O}_{3}$. On the other hand, during winter, faster upward transport and better dynamical isolation of the tropics reduce the effect of in-mixing to values of around $20 \%$. This seasonality of transport was also suggested by Yang et al. [2008] who found that during boreal summer the upward mass flux has a near-zero minimum around $70 \mathrm{hPa}$ and, consequently, the mass flux below this level is decoupled from that above. Note that because $\mathrm{O}_{3}$ does not behave as a passive tracer, the mentioned percentages of inmixing are related only to $\mathrm{O}_{3}$ and estimate the lower bound of the horizontal transport into the lower tropical stratosphere.

[33] There are also some other limitations on our simple estimate. First, our analysis does not allow us to say whether the isentropic in-mixing is a purely advective or diffusive process. Furthermore, the direction of in-mixing (from the southern or from the northern extratropics) cannot be determined either, so we now discuss some additional arguments known from the literature.

[34] A weak and permeable subtropical jet in the summer northern hemisphere [Chen, 1995; Haynes and Shuckburgh, 2000] indicates that this in-mixing can be understood as enhanced meridional transport from the northern extratropics into the TTL. In addition, the most pronounced hemispheric asymmetry of the climatological flow pattern in the vicinity of the tropopause originates from the Asian summer monsoon that manifests as a strong anticyclone in the upper troposphere [Dethof et al., 1999; Randel and Park, 2006; Park et al., 2007]. Thus enhanced in-mixing of $\mathrm{O}_{3}$ in summer is likely driven by the Asian summer monsoon extending well into the lower stratosphere (up to about $20 \mathrm{~km}$ or $\theta=420 \mathrm{~K}$ [Randel and Park, 2006]).

[35] The strong hemispheric differences in isentropic transport were also discussed by Tuck et al. [1997] using backward trajectories (Figure 18) and by Chen [1995] using a semi-Lagrangian transport model. Chen [1995] showed that enhanced equatorward transport on $\theta$ surfaces between 340 and $380 \mathrm{~K}$ occurs both during summer and during winter (semiannual cycle) and that this transport is most 
intensive from the northern summer hemisphere (annual cycle). This supports also our interpretation of the differences between the HALOE and SHADOZ-based results. SHADOZ observations sample the southern hemisphere more effectively and, consequently, enhance the relative contribution of the semiannual in comparison to the annual cycle.

[36] In contrast to the absolute values, the annual cycle of in-mixing is a very robust feature of our analysis. Finally, our study also shows that the picture of the TTL where " $\mathrm{O}_{3}$-poor air of tropospheric origin enters and rises slowly in near isolation" [Avallone and Prather, 1997] should be revised, in particular between 380 and $440 \mathrm{~K}$, by a picture of the TTL where the annual cycle of upwelling and inmixing modulates the composition of air within the TTL.

[37] Acknowledgments. We are very grateful for the contributions of William J. Randel and Michael Volk who critically accompanied this work. We thank Mijeong Park for providing us with SHADOZ-based $\mathrm{O}_{3}$ climatology. The European Centre for Medium-Range Weather Forecasts (ECMWF) is acknowledged for meteorological data support. We thank the three reviewers for their substantive comments, which helped improve the manuscript significantly.

\section{References}

Avallone, L. M., and M. J. Prather (1997), Tracer-tracer correlations: Three-dimensional model simulations and comparisons to observations, J. Geophys. Res., 102, 19,233-19,246.

Becker, G., J.-U. Grooß, D. S. McKenna, and R. Müller (2000), Stratospheric photolysis frequencies: Impact of an improved numerical solution of the radiative transfer equation, J. Atmos. Chem., 37, 217-229, doi:10.1023/A:1006468926530.

Bhatt, P. P., E. E. Remsberg, L. L. Gordley, J. M. McInerney, V. G. Brackett, and J. M. Russell (1999), An evaluation of the quality of Halogen Occultation Experiment ozone profiles in the lower stratosphere, J. Geophys. Res., 104, 9261-9275.

Brühl, C., et al. (1996), Halogen Occultation Experiment ozone channel validation, J. Geophys. Res., 101, 10,217-10,240.

Callaghan, P. F., and M. L. Salby (2001), Three-dimensionality and forcing of the Brewer-Dobson circulation, J. Atmos. Sci., 59, 976-991.

Chen, P. (1995), Isentropic cross-tropopause mass exchange in the extratropics, J. Geophys. Res., 100, 16,661-16,673.

Dethof, A., A. O’Neill, J. M. Slingo, and H. G. J. Smit (1999), A mechanism for moistening the lower stratosphere involving the Asian summer monsoon, Q. J. R. Meteorol. Soc., 556(125), 1079-1106.

Folkins, I., M. Loewenstein, J. Podolske, S. J. Oltmans, and M. Proffitt (1999), A barrier to vertical mixing at $14 \mathrm{~km}$ in the tropics: Evidence from ozonesondes and aircraft measurements, Geophys. Res. Lett., 104, 22,095-22,102.

Folkins, I., P. Bernath, C. Boone, G. Lesins, N. Livesey, A. M. Thompson, K. Walter, and J. C. Witte (2006), Seasonal cycles of $\mathrm{O}_{3}, \mathrm{CO}$, and convective outflow at the tropical tropopause, Geophys. Res. Lett., 33, L16802, doi:10.1029/2006GL026602.

Fueglistaler, S., B. Legras, A. Beljaars, J.-J. Morcrette, A. Simmons, A. M. Tompkins, and S. Uppapla (2008), The diabatic heat budget of the upper troposphere and lower/mid stratosphere in ECMWF reanalysis, $Q$. J.R. Meteorol. Soc., 110, 1-27, doi:10.1002/qj.000.

Fueglistaler, S., A. E. Dessler, T. J. Dunkerton, I. Folkins, Q. Fu, and P. W. Motte (2009), Tropical tropopause layer, Rev. Geophys., 47, RG1004, doi:10.1029/2008RG000267.

Grooß, J.-U., and J. M. Russell (2005), Technical note: A stratospheric climatology for $\mathrm{O}_{3}, \mathrm{H}_{2} \mathrm{O}, \mathrm{CH}_{4}, \mathrm{NO}_{x}, \mathrm{HCl}$ and $\mathrm{HF}$ derived from HALOE measurements, Atmos. Chem. Phys., 5, 2797-2807.

Haynes, P., and E. Shuckburgh (2000), Effective diffusivity as a diagnostic of atmospheric transport: 2. Troposphere and lower stratosphere, J. Geophys. Res., 105, 22,795-22,810.

Haynes, P. H., C. J. Marks, M. E. McIntyre, T. G. Shepherd, and K. P. Shine (1991), On the "downward control" of extratropical diabatic circulations by eddy-induced mean zonal forces, J. Atmos. Sci., 48, 651-678.

Holton, J. R. (1992), An Introduction to Dynamic Meteorology, Acad. Press, London, U.K.

Holton, J. R., P. Haynes, M. E. McIntyre, A. R. Douglass, R. B. Rood, and L. Pfister (1995), Stratosphere-troposphere exchange, Rev. Geophys., 33, $403-439$.
Krüger, K., S. Tegtmeier, and M. Rex (2008), Long-term climatology of air mass transport through the Tropical Tropopause Layer (TTL) during NH winter, Atmos. Chem. Phys., 8, 813-823.

Liu, C., E. Zipser, T. Garrett, J. H. Jiang, and H. Su (2007), How do the water vapor and carbon monoxide "tape recorder" starts near the tropical tropopause?, Geophys. Res. Lett., 34, L09804, doi:10.1029/ 2006GL029234.

Marcy, T. P., et al. (2007), Measurements of trace gases in the tropical tropopause layer, Atmos. Environ., 41, 7253-7261.

Mote, P. W., T. J. Dunkerton, M. E. McIntyre, E. A. Ray, P. H. Haynes, and J. M. Russell III (1998), Vertical velocity, vertical diffusion, and dilution by midlatitude air in the tropical lower stratosphere, J. Geophys. Res., $103,8651-8666$.

Niwano, M., K. Yamazaki, and M. Shiotani (2003), Seasonal and QBO variations of ascent rate in the tropical lower stratosphere as inferred from UARS HALOE trace gas data, J. Geophys. Res., 108(D24), 4794, doi:10.1029/2003JD003871.

Osterman, G. B., R. J. Salawitch, B. Sen, G. C. Toon, R. A. Stachnik, H. M. Pickett, J. J. Margitan, and D. B. Peterson (1997), Balloonborne measurements of stratospheric radicals and their precursors: Implications for the production and loss of ozone, Geophys. Res. Lett., 24, 1107-1110, doi:10.1029/97GL00921.

Park, M., W. J. Randel, L. K. Emmons, P. F. Bernath, K. A. Walker, and C. D. Boone (2007), Chemical isolation in the Asian monsoon anticyclone observed in Atmospheric Chemistry Experiment (ACE-FTS) data, Atmos. Chem. Phys., 8, 757-764.

Plöger, F., P. Konopka, G. Günther, J.-U. Grooß, and R. Müller (2009), Impact of the vertical velocity scheme on modeling transport across the tropical tropopause layer, J. Geophys. Res., doi:10.1029/2009JD012023, in press.

Plumb, R. A. (1996), A "tropical pipe" model of stratospheric transport, J. Geophys. Res., 101, 3957-3972.

Randel, W. J., and M. Park (2006), Deep convective influence on the Asian summer monsoon anticyclone and associated tracer variability observed with Atmospheric Infrared Sounder (AIRS), J. Geophys. Res., 111, D12314, doi:10.1029/2005JD006490.

Randel, W. J., M. Park, F. Wu, and N. Livesey (2007), A large annual cycle in ozone above the tropical tropopause linked to the Brewer-Dobson circulation, J. Atmos. Sci., 64, 4479-4488.

Reed, R. J., and C. L. Vlcek (1969), The annual temperature variation in the lower tropical stratosphere, J. Atmos. Sci., 26, 163-167.

Schoeberl, M. R., A. R. Douglass, Z. X. Zhu, and S. Pawson (2003), A comparison of the lower stratospheric age spectra derived from a general circulation model and two data assimilation systems, J. Geophys. Res., 108(D3), 4113, doi:10.1029/2002JD002652.

Schoeberl, M. R., S. R. Kawa, A. R. Douglass, J. Waters, N. Livesey, W. Read, and M. Filipiak (2006), The carbon monoxide tape recorder, Geophys. Res. Lett., 33, L12811, doi:10.1029/2006GL026178.

Schoeberl, M. R., A. R. Douglass, R. S. Stolarski, S. Pawson, S. E. Strahan, and W. Read (2008), Comparison of lower stratospheric tropical mean vertical velocities, J. Geophys. Res., 113, D24109, doi:10.1029/ 2008JD010221.

Simmons, A., S. Uppala, S. Dee, and S. Kobayashi (2006), ERA-Interim: New ECMWF reanalysis products from 1989 onwards, ECMWF Newsl., $110,25-35$

Thompson, A. M., J. C. Witte, H. G. J. Smit, S. J. Oltmans, B. J. Johnson, V. W. Kirchhoff, and F. J. Schmidlin (2007), Southern Hemisphere Additional Ozonesondes (SHADOZ) 1998-2004 tropical ozone climatology: 3. Instrumentation, station-to-station variability, and evaluation with simulated flight profiles, J. Geophys. Res., 112, D03304, doi:10.1029/2005JD007042.

Tuck, A. F., et al. (1997), The Brewer-Dobson circulation in the light of high altitude in situ aircraft observation, $Q$. J. R. Meteorol. Soc., 123, $1-69$.

Volk, C. M., et al. (1996), Quantifying transport between the tropical and mid-latitude lower stratosphere, Science, 272, 1763-1768.

Wennberg, P. O., et al. (1998), Hydrogen radicals, nitrogen radicals, and the production of $\mathrm{O}_{3}$ in the upper troposphere, Science, 279, 49-53.

Yang, Q., Q. Fu, J. Austin, A. Gettelman, F. Li, and H. Vömel (2008), Observationally derived and general circulation model simulated tropical stratospheric upward mass fluxes, J. Geophys. Res., 113, Q00807, doi:10.1029/2008JD009945.

J.-U. Grooß, P. Konopka, R. Müller, and F. Plöger, ICG-1: Stratosphere, Forschungszentrum Jülich, D-52425 Jülich, Germany. (p.konopka@fzjuelich.de) 